Article

\title{
The Impact of Transformational Leadership on Employee Sustainable Performance: The Mediating Role of Organizational Citizenship Behavior
}

\author{
Weiping Jiang ${ }^{1, *} \mathbb{1}$, Xianbo Zhao ${ }^{2}$ and Jiongbin $\mathrm{Ni}^{1}$ \\ 1 School of Civil Engineering, Shenzhen University, Shenzhen 518060, China; nijiongbin@163.com \\ 2 School of Engineering and Technology, Central Queensland University, Sydney, NSW 2000, Australia; \\ b.zhao@cqu.edu.au \\ * Correspondence: swingopen@szu.edu.cn; Tel.: +86-0755-2601-3879
}

Received: 18 August 2017; Accepted: 31 August 2017; Published: 4 September 2017

\begin{abstract}
Transformational leadership has drawn extensive attention in management research. In this field, the influence of transformational leadership on employee performance is an important branch. Recent research indicates that organizational citizenship behavior plays a mediating role between transformational leadership and employee performance. However, some of these findings contradict each other. Given the background where greater attention is being paid to transformational leadership in the construction industry, this research aims to find the degree of the influence of transformational leadership on employee sustainable performance, as well as the mediating role of organizational citizenship behavior. A total of 389 questionnaires were collected from contractors and analyzed via structural equation modeling. The findings reveal that employee sustainable performance is positively influenced by transformational leadership. In addition, more than half of that influence is mediated by their organizational citizenship behavior. These findings remind project managers of the need to pay close attention to transformational leadership, to cultivate organizational citizenship behavior, and thereby to eventually improve employee's sustainable performance.
\end{abstract}

Keywords: transformational leadership; sustainable performance; organizational citizenship behavior; structural equation modeling

\section{Introduction}

A construction project has tasks with relatively high complexity and uncertainty. These tasks are completed by project participants, who need to be coordinated [1-3]. Thus, the role of project managers is particularly important, especially in the formation of rules and the development of collective spirit of cooperation. Transformational leadership refers to a leader inspiring followers to do their best [4], and can meet the requirements of project-oriented organizations, especially in emphasizing vision and inspiring roles [5]. Indeed, transformational leadership needs to be considered in construction projects in China. This is mainly because project employees in the Chinese construction industry are inclined to change jobs frequently. The turnover rate in the construction industry is high, largely due to the unstable and atrocious work environment [6]. Even if an employee chooses to stay on a project, he or she may work at only low levels of efficiency [7]. In such circumstances, project managers are required to show personal charisma, and transformational leadership is a suitable means by which to do so [1]. From a long-term perspective, a high turnover rate is harmful to any project's sustainability. By definition, human development is at the very core of sustainable development. Accordingly, the retention of talents and supporting the development of those talents are important constituents of project sustainability. Transformational leadership may be a useful strategy and tool for project managers to use, in order to achieve sustainable project development. 
In the background of promoting project sustainability [8], this research presents employees' sustainable performance (in Section 2.1.2) based on the concept of job performance. The purpose of this research is to explore the influence of project managers' transformational leadership on project employees' sustainable performance. The researchers also examine the mediating role of organizational citizenship behavior. Most previous research has focused on the direct impact of transformational leadership on outcomes, such as follower performance [9], organizational effectiveness [10], team performance [11], and turnover intention [12]. A few studies have also focused on the mediation role of organizational citizenship behavior (OCB) in the relationship between transformational leadership and different outcomes [13-15]. However, the results of some former studies contradict each other. Boerner et al. [13] found that the influence of transformational leadership on employee performance is not mediated by OCB in banks. However, Ekowati et al. [14] confirmed in an empirical study that follower performance is improved by transformational leadership by stimulating organizational citizenship behavior. More empirical research is needed to test the mediating role of organizational citizenship behavior in the relationship between transformational leadership and employee performance. Moreover, similar studies pertaining to the construction industry are extremely rare. Therefore, this research would improve the understanding of the function of transformational leadership in construction projects by examining the influence of transformational leadership on employee sustainable performance through empirical study.

Based on a sample of project managers and their subordinates in China, our findings suggest that transformational leadership has a significant influence on employee sustainable performance, mainly through the mediation of organizational citizenship behavior. These findings add to the growing body of literature that suggests transformational leadership may be a predictor of employee performance in two aspects. First, this research provides empirical support for the view that OCB mediates the influence of transformational leadership on employee performance. Second, it also reminds researchers and practitioners of paying close attention to transformational leadership and stimulating OCB to improve employee sustainable performance.

\section{Theoretical Background and Hypothesis Development}

Construction projects are comprised of different types of participants with different demands. However, the participants have a common goal, which is to complete the construction tasks within budget limitations and before the deadline $[16,17]$. Contactors are the main performers and finishers of construction tasks. The project manager is required to call on a high level of leadership ability, in order to motivate all project employees.

According to the leader-member exchange theory, a social exchange relationship exists between the leader and the followers. On one side, the employee earns extra rewards from the leader for excellent performance. On the other side, the leader (or the organization) achieves a high level of performance but at the cost of those incentives. It is worth noting that social exchange does not only refer to material interests but also spiritual and psychological benefits [18].

The employees would be expected to show reciprocal behavior as a response to the perceived leader's behavior [19]. It is well recognized that, employee organizational citizenship behavior is an important constituent of their overall behavior and has a critical influence on job performance.

\subsection{Transformational Leadership and Employee Sustainable Performance}

\subsubsection{Transformational Leadership}

Transformational leadership theory has developed into a hot topic in management research [20]. Transformational leadership theory was first proposed by Burns [21], and then advanced by Bass [4], who made an outstanding contribution to the development of the theory. A transformational leader transforms the followers thinking in such a way that they adopt the vision of the organization as if 
that vision was their own. This transformation motivates employees to overcome their own interests and strive for the collective goals [22].

Four dimensions of transformational leadership have been put forward [23,24]. They are (1) idealized influence, (2) inspirational motivation, (3) intellectual stimulation behavior, and (4) individualized consideration. Idealized influence refers to the extent to which a leader is engaging in promoting the follower to generate trust and follow the leader [25]. Inspirational motivation characterizes the extent to which a leader presents a vision to motivate followers. Thirdly, intellectual stimulation characterizes the extent to which a leader encourages followers to innovate and challenge themselves. Finally, individual consideration characterizes the extent to which the leader cares about the followers' individual needs.

\subsubsection{Employee's Sustainable Performance}

Research into job performance has a rich history in the fields of marketing [26], management [27], and psychology [28]. Zablah et al. [29] defined job performance as the extent to which an employee contributes to organizational effectiveness, given the expectations associated with his/her work role.

Katz and Kahn [30] first divided job performance into task performance and contextual performance. Following this, abundant work has been done relevant to the various dimensions of job performance. In addition, Borman and Motowidlo's [31] work has been accepted by most relevant studies [32]. The present study adopts Borman and Motowidlo's [31] classification of job performance. Task performance can be defined as the effectiveness of activities contributing to organization operation. Unlike task performance, contextual activities contribute to organizational effectiveness by shaping the social and cultural contexts that serve as the catalyst for task activities and processes [33]. Contextual performance is an important element of job performance, and is also called relational performance.

With consideration of the tendency of focus on sustainability in project management, the concept of employee sustainable performance is put forward in this research. Employee sustainable performance refers to an employee's contribution to his/her own sustainable development and project organization sustainable development, and is divided into task sustainable performance and relation sustainable performance. Task sustainable performance refers to the extent to which employees achieve their own sustainable development by fulfilling their tasks. Relational sustainable development refers to the extent to which employees contribute to the sustainable development of project organizations in promoting organizational culture.

Numerous studies have examined the relationship between transformational leadership and employee performance [34,35]. In this paper, the relationship between transformational leadership and employee sustainable performance is discussed in Section 2.1.3.

\subsubsection{The Relationship between the Above Two Concepts}

The influence of transformational leadership on employee performance has recently become a hot research topic. Many findings reveal that transformational leadership has a positive and important effect on employee job performance $[7,16,36,37]$. Due to the openness, complexity, and challenges presented by many projects, transformational leadership is advocated [38,39]. This kind of leadership is believed to be particularly suitable for project organization [40]. Project managers are advised to use more transformational leadership as a means to motivate employees [41].

Bass [42] believed that transformational leadership inspires followers to find new ways to face challenges and solve problems. Owing to the unique outcomes that often accompany many projects [43], novel and uncertain means are often required to achieve project goals. The leader must encourage these traits and allow participants to act with a certain degree of independence [44,45], rather than the leader merely giving instruction [46].

Transformational leaders play the roles of both coach and advisor. A one-to-one relationship improves the commitment of team members to take on the tasks arranged by the leader [47]. First, a transformational project manager is concerned with each employee with different needs 
under different professional backgrounds. The transformational leader would supply opportunity for employees to sustainably develop [48,49]. Second, the project manager as the head of the project, consciously cultivates the spirit of collectivism culture and conducts individuals to participate in collective activities and interact with each other nicely [22]. All these behaviors are beneficial to the employees' relation sustainable performance.

Moreover, charisma (as an important element of transformational leadership) seems to be particularly important to projects. This is because project leaders have relatively less authority and influence on their followers than do line managers [50].

Taking all of the above consideration into account, the researchers hypothesize the following:

Hypothesis 1a (H1a). Idealized influence has a positive influence on employee task sustainable performance.

Hypothesis $\mathbf{1 b}(\mathbf{H 1 b})$. Idealized influence has a positive influence on employee relation sustainable performance.

Hypothesis 1c (H1c). Inspirational motivation has a positive influence on employee task sustainable performance.

Hypothesis 1d (H1d). Inspirational motivation has a positive influence on employee relation sustainable performance.

Hypothesis 1e (H1e). Intellectual stimulation behavior has a positive influence on employee task sustainable performance.

Hypothesis $1 \mathbf{f}(\mathbf{H 1 f})$. Intellectual stimulation behavior has a positive influence on employee relation sustainable performance.

Hypothesis $1 \mathbf{g} \mathbf{( H 1 g ) . ~ I n d i v i d u a l i z e d ~ c o n s i d e r a t i o n ~ h a s ~ a ~ p o s i t i v e ~ i n f l u e n c e ~ o n ~ e m p l o y e e ~ t a s k ~ s u s t a i n a b l e ~}$ performance.

Hypothesis $1 \mathrm{~h}(\mathbf{H} 1 \mathbf{h})$. Individualized consideration has a positive influence on employee relation sustainable performance.

\subsection{The Mediating Role of Organizational Citizenship Behavior (OCB)}

\subsubsection{Introduction to $\mathrm{OCB}$}

The interest in OCB has been increasing ever since the concept was first introduced in 1983, and many related concepts have been influenced by OCB [51]. This popularity can be attributed to the managerial relevance of $\mathrm{OCB}$, especially its effects on organizational functioning [51].

Organ [52] defined OCB as individual behavior that is not clearly described by the formal reward system and can improve the effectiveness of the organization's functioning.

Many types of OCB have been put forward by scholars under different contexts. Organ [52] put forward five dimensions of $\mathrm{OCB}$, including (1) helping behavior, (2) conscientious behavior, (3) sportsmanship, (4) courtesy, and (5) civic virtue. Based on a literature review, Podsakoff and Mackezie [53] further summarized seven types of $O C B$, namely (1) helping behavior, (2) sportsmanship, (3) organizational loyalty, (4) organizational compliance, (5) individual initiative, (6) civic virtue, and (7) self-development. These types of OCB are still widely used in relevant and related studies.

Farh et al. [54] examined the different forms of OCB in the People's Republic of China and actually suggested that there are 10 forms of OCB. As such, OCB in China is believed to be different from its Western counterparts and is embedded in its unique social and cultural background. These 10 forms of OCB are widely used in studies directly pertaining to Chinese culture.

Given the OCB of possibly too many dimensions, summarized by Farh et al. [54], some Chinese scholars put forward a five-dimension OCB model, based on the work of Farh et al. [54] and Podsakoff et al. [55], combined with the context of Chinese culture [56]. These five dimensions are (1) taking initiative, (2) helping co-workers, (3) participating in group activities, (4) self-development and (5) saving company resources [56]. Taking initiative refers to behavior indicating one's willingness 
to take the work not in the scope of duties, such as working overtime and taking additional responsibility [54]. Helping co-worker refers to helping fellow workers with tasks related with the organization or with private matters. This dimension has similarities to altruism [57] or helping [58] in Western literature. However, the concept of helping co-workers in China has a broader scope than altruism in Western society, where altruism is usually relevant to organizational tasks. In China, helping a co-worker includes helping with the co-worker's private matters. Participation in group activities refers to taking part in activities organized by the organization or special groups [54]. This dimension is similar to civic virtue in Western literature [52,55,59], since both refer to participation in an organization's activities. However, civic virtue is a broader concept concerning organizational life and includes keeping to organizational announcements, memos, and so on [55]. Self-development refers to improving one's own knowledge or skills through self-learning [54,60]. Saving company resources refers to saving organizational resources and protecting the company from losses. This dimension was not found in Western literature and was first discovered in Taiwan [61].

\subsubsection{The Mediating Role of OCB}

Scholars have found in many studies in recent years that OCB is treated as a mediated variable, with outcome variables such as employee performance [14,62], organization performance [63], and individual creativity [64]. Research similar and helpful to this research exists [14,62]. However, differences also exist. First, the independent variable used is different. For example, Khokhar and Zia-ur-Rehman [62] researched the influence of ethical leadership on employee performance. Secondly, the research context is different to this research. Maharani et al. [14] studied OCB in banking and added another independent variable (job satisfaction).

Transformational leadership emphasizes the importance of social exchange between leader and follower in the form of a psychological contract, thus stimulating OCB [14]. In addition, OCB comprises extra-role behaviors that are important for efficient processes within an organization [65]. Podsakoff et al. [53] found that OCB can also predict follower performance.

Taking the initiative offers many opportunities for an employee willing to take on additional work responsibility and face work problems independently. Therefore, such employees have many chances to improve their work competency and their profession sustainable development. Helping behavior improves employee performance. This is because colleagues are more easily integrated into a complete group. Therefore, the group can build up best practices, and make communication and task coordination easier. Therefore, helping behavior could improve group work performance, as well as individual work performance. All these kinds of performances are beneficial to both task sustainable performance and relational sustainable performance. Participation in group activities can stimulate organizational culture, which would in turn strengthen organizational cohesion and improve group work performance. Participation in group activities can make work cooperation run more smoothly, and both task sustainable performance and relation sustainable performance could also be improved. Self-development can improve an employee's knowledge and work skills, and eventually improve his or her task sustainable performance. Saving company resources means an employee has a spirit of dedication to the organization. This spirit will in turn stimulate the employee to try his best to perform the necessary work. Therefore, saving company resources has a positive influence on employee sustainable performance.

Therefore, it is hypothesized that:

Hypothesis 2a (H2a). Transformational leadership has a positive influence on employee organizational citizenship behavior.

Hypothesis $\mathbf{2 b} \mathbf{( H 2 b ) . ~ E m p l o y e e ~ o r g a n i z a t i o n a l ~ c i t i z e n s h i p ~ b e h a v i o r ~ h a s ~ a ~ p o s i t i v e ~ i n f l u e n c e ~ o n ~ e m p l o y e e ~}$ sustainable performance. 


\section{Methodology}

\subsection{Sample}

\subsubsection{Sample Selection}

Generally, there are two kinds of sampling method: probability sampling and non-probability sampling [65]. Probability sampling has the advantages in getting multi-source information and inferring the information of the entire population because it involves the study of a randomly selected sample. However, in the construction industry, it is challenging and not feasible to complete a randomly selected sample in many cases. Therefore, non-probability sampling is always adopted in construction research [66]. This research adopted the latter method and was conducted in China and involved five provinces (Jiangsu, Zhejiang, Guangdong, Hubei, and Shandong) and one district (Shanghai). These provinces and district each have certain degrees of representativeness of the construction industry in China.

As previous studies have shown that different individual perspectives are valid where transformational leadership ratings are concerned $[36,67,68]$, the researchers focus on individual-level responses. In view of the problem of date homology variance, this research investigated project managers and employees, respectively. Project managers were asked about project characteristics and asked to evaluate their employees' sustainable performance. Employees were asked about their transformational leadership. Strict conditions were applied to the questionnaire respondents and their projects. Construction projects were required to have begun more than six months prior to this study and have more than six months remaining before completion. Furthermore, project teams were required to have operated stably for more than three months, with project employees and project managers fully familiar with each other. Respondents were required to have a harmonious relationship with other team members and have a certain mass base.

\subsubsection{Sample Size}

This research used a maximum likelihood (ML) estimation method in fitting the calculation of a structural equation model. Considerable studies have found that the success of the ML estimation method is dependent on the sample size [69]. When the sample size is small, there will be a high non-convergent and inappropriate solution ratio. Generally, when the sample size is larger, the accuracy of estimation is higher in the analysis of structural equation modeling. However, there is no uniform standard for a "large sample". Different research backgrounds and categories have different requirements for the optimum number of samples. The statistical power evaluation method is recommended to calculate the sample size [70]. Generally, 0.8 is the critical value for statistical power for the minimum sample size [7].

Taking into account the questionnaire response rate and the uncontrollable factors in our investigation, the sample size of this study was 500. This was far more than the minimum sample size (approximately 250), which was calculated using the method provided by Muthen and Muthen [70].

\subsection{Data Collection Procedure}

In order to increase the response rate and improve the reliability of the questionnaires, this research included two measures in the large sample survey. First, it was emphasized that the questionnaires were anonymous and not collected by any third person but by the researchers themselves. This measure dispelled respondents' concerns about information leakage and the determination of the relationships between leaders and subordinates. Second, in order to improve the authenticity and quality of the data, the researchers selected other members of the project team to conduct telephone reviews, in order to improve the representation of the questionnaires. All the steps were as follows:

(1) Before the formal investigation, the researchers explained the purpose of this study, the questionnaire issuing and collection process, and precautions to be taken when filling out the questionnaires. 
(2) Paper questionnaires were sealed into large envelope bags and sent to the respondents. When questionnaires were sent by e-mail, the questionnaires were sent back to the investigators without any third-party participation.

(3) The investigators confirmed that all the questionnaires were collected, and ensured that the privacy of all respondents was protected.

(4) The investigators selected other team members to review the representative nature and reliability of the collected questionnaires.

After revising the questionnaire, our large-scale questionnaire investigation began in May, 2015. Areas covered included Shanghai, Jiangsu, Zhejiang, Guangdong, Hubei, and Shandong in China. The investigation objects were project team members and project managers (in pairs) in construction projects, which had lasted at least six months and would last for more than another six months. A total of 500 questionnaires were issued. The period of the issue and collection of questionnaires lasted more than six months. A total of 389 questionnaires were collected, involving 389 project teams. The questionnaire recovery rate was therefore approximately $77.8 \%$.

\subsection{Measures}

Three variables were to be measured in this study, including transformational leadership, $\mathrm{OCB}$, and employee sustainable performance. The measurement items of the three variables were obtained via rigorous steps. First, measurement items were adopted from both domestic and overseas studies. Also, any items prepared by Chinese scholars were paid particular attention, because this study was specifically conducted with regard to Chinese construction projects. Second, taking into account the cultural background of China, in-depth interviews and group discussions were used to optimize measurement items. Third, a small sample test was employed, in order to remove the items not significantly related to the variables by a reliability analysis and exploratory factor analysis. Then, the measurement scales of the formal questionnaires were achieved.

The transformational leadership items were adopted by Bass and Avolio [23] and tested with construction project teams in Shenzhen, a Chinese city with a well-developed construction industry. The idealized influence subscale had eight items (after deleting two items). The inspirational motivation, intellectual stimulation and individual consideration subscales retained all the items (respectively four, four, and five items). Cronbach's $\alpha$ of the four subscales were $0.860,0.764,0.787$, and 0.780 , respectively.

The OCB items were adopted form Wei et al [56], whose design was based on the work of Farh et al. [54] and Podsakoff et al. [55]. The self-development and taking initiative subscales were both retained after the small sample test, and both had five items. The saving company resources subscale's Cronbach's $\alpha$ was 0.518, which was under the critical value (0.6). The reason for this result could be that there were four reverse items, which could easily be filled in wrongly because of fixed ways of thinking or even carelessness. Therefore, this subscale was left out after serious consideration. The participation in group activities subscale retained three items of 5 , and the helping coworker subscale retained four items of 5 . Cronbach's $\alpha$ of the four remaining subscales were $0.839,0.798,0.719$, and 0.720 , respectively.

Employee sustainable performance was classified as task sustainable performance and relation sustainable performance. In addition, the items were adopted from Han et al.'s [71] study in China and modified by adding the meaning of sustainability. The task sustainable performance subscale retained all 10 items. Also, the relation sustainable performance subscale retained seven of the 10 items. Cronbach's $\alpha$ were 0.907 and 0.926 , respectively.

After the small sample test, the hypotheses were clearer and exactly as shown in Appendix A (Table A1). Responses were given on a 7-point scale, from 1 (not at all) to 7 (very often). 


\subsection{Structural Equation Modeling}

Structural equation modeling (SEM) was adopted in this study as a means by which to test the proposed hypotheses. The SEM method has specific advantages when conducting empirical research in the field of construction project management, as follows: (1) SEM can deal with multiple variables at the same time; (2) SEM allows both the independent and dependent variables to contain measurement errors; (3) SEM can estimate the degree of fit of the entire model containing all the constructs [72].

In practice, SEM consists of six steps [7,73,74], namely (1) questionnaire design, (2) pilot testing, (3) large-sample data collection, (4) running of the model, (5) model validation and revision, and (6) analysis of the final results. The first three steps are described in this section, and the last three steps are covered in the following sections.

There are several indices that can be used to evaluate the goodness fit of the model. First, one can use basic indices, such as $\chi^{2} / \mathrm{df}$, which is less than 3 when indicating a good model fit $[75,76]$, and RMSEA, which is less than 0.1 [77]. Secondly, other goodness indices can be used. CFI (comparative fit index), NFI (normed fit index), and IFI (incremental fit index) were used to evaluate the model. CFI and NFI above the threshold value of 0.9 , indicate a good model fit $[78,79]$. The covariance-based SEM calculation was executed by using AMOS 21.0, which is a professional software program designed for SEM analysis.

\section{Analyses and Results}

The calculation results show that the model was acceptable with high-fit indices. $\chi^{2} / \mathrm{df}=1.956$, RMSEA $=0.0496, \mathrm{CFI}=0.983, \mathrm{IFI}=0.983, \mathrm{NFI}=0.967$. In the measurement model, the factor load of all observed variables is positive and significant, and all measurement errors are positive. In the structural model, the absolute values of all the path coefficients were less than 1 . The path map is shown in Figure 1, and the values of the paths are shown in Appendix A (Table A2).

It can be seen from Table 1 that, in our study, inspirational motivation leadership had no direct effect on the task sustainable performance. Also, idealized influence and intellectual stimulation of the transformational leadership had no direct effect on the self-development of OCB. Helping behavior had no significant effect on relation sustainable performance. All the paths were significant, except the above-mentioned four paths. After deleting these four paths, the fit result was better: $\chi^{2} / \mathrm{df}=1.877$, RMSEA $=0.0476, \mathrm{CFI}=0.984, \mathrm{IFI}=0.984, \mathrm{NFI}=0.968$. According to previous studies, the model was acceptable.

In addition, the influence of transformational leadership on employee sustainable performance can be classified as direct and indirect (mediated by OCB), exactly as shown in Table 1. As can be seen from the table, OCB mediated more than half the influence of transformational leadership on employee sustainable performance.

Table 1. The mediating role of organizational citizenship behavior (OCB).

\begin{tabular}{cccc}
\hline From & To & Direct Influence & Indirect Influence \\
\hline \multirow{2}{*}{ Idealized influence } & Task sustainable performance & 0.104 & 0.210 \\
\cline { 2 - 4 } & Relation sustainable performance & 0.216 & 0.139 \\
\hline \multirow{2}{*}{ Inspirational motivation } & Task sustainable performance & 0 & 0.244 \\
\cline { 2 - 4 } & Relation sustainable performance & 0.193 & 0.157 \\
\hline \multirow{2}{*}{ Intellectual stimulation } & Task sustainable performance & 0.116 & 0.171 \\
\cline { 2 - 4 } & Relation sustainable performance & 0.155 & 0.113 \\
\hline \multirow{2}{*}{ Individualized consideration } & Task sustainable performance & 0.115 & 0.241 \\
\cline { 2 - 4 } & Relation sustainable performance & 0.154 & 0.173 \\
\hline & Total & 1.053 & 1.448 \\
\hline
\end{tabular}




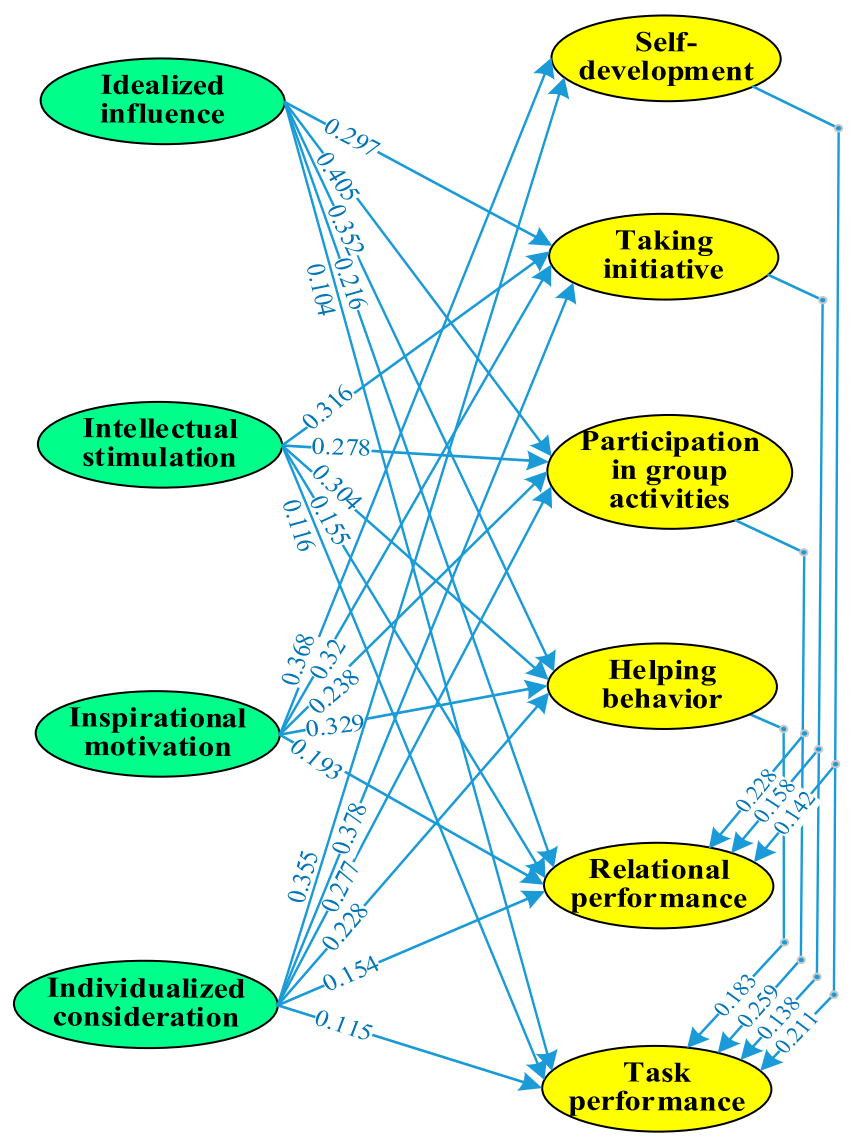

Figure 1. Structural equation model (SEM) for transformational leadership and employees' sustainable performance.

\section{Discussion}

\subsection{The Influence of Transformational Leadership on Employee Sustainable Performance}

The above result indicates that transformational leadership has a positive influence on employee sustainable performance, except for inspirational motivation, which had an indistinct influence on task sustainable performance. Leaders with transformational leadership can help subordinates to achieve the set goal by cultivating a high degree of collectivism and a harmonious relationship between the leader and the subordinates [10]. Further, transformational leadership using emotional means (such as individual consideration) could easily improve the employees' sense of belonging, thus improving both the task sustainable performance and relation sustainable performance of those employees $[9,18]$. However, this study found that inspirational motivation does not directly influence task sustainable performance. The reason for this finding may be that project management tasks are often intertwined, and task completion relies more on team collaboration [5,7]. Therefore, incentives do not significantly impact task sustainable performance.

In addition, of particular interest is the finding that the influence of transformational leadership on relation to sustainable performance is significantly stronger than the influence on task sustainable performance. Transformational leaders attempt to link the leader and subordinates together and create a cooperative and transformational atmosphere [2,4,21-24]. Transformational leadership improves the leader-subordinate relationship and organizational climate, which in turn helps employees to improve the spirit of collectivism and do more work outside of and in addition to their own duties, but work which is beneficial to organizational development. Therefore, transformational leadership has a stronger impact on relation sustainable performance. 


\subsection{The Influence of Transformational Leadership on Employee OCB}

Researchers have testified that all dimensions of transformational leadership have a positive influence on the various dimensions of $\mathrm{OCB}$, except for idealized influence and intellectual stimulation for self-development. As transformational leadership emphasizes cultivating employee collectivism and helping employees achieve extraordinary goals, it then becomes easy for employees to show organizational citizenship behavior $[18,33]$.

Idealized influence requires the leader to be confident and powerful, and to influence the subordinates with the leader's values and beliefs [25]. Intellectual stimulation means the leader stimulates employees to think creatively and find solutions to difficult problems. Neither of these two dimensions of transformational leadership have any significant influence on employee self-development. There are two main reasons for this. First, employees have to get along with the leader for a long time, and aesthetic fatigue may emerge. Moreover, in China, there is a saying that goes, "far sweet, near smelly". This basically means that if two people are familiar with each other, the shortcomings of one person are likely to be exposed, and a good first impression may be destroyed. Therefore, idealized influence can hardly affect employee self-development. Secondly, employees are familiar with the rules and systems within the project organization. These employees can manage themselves well and use their own experience to start work. Intellectual stimulation could improve employee sustainable performance, but this may not affect their behavior. Furthermore, employees may have a stereotypical thinking pattern and take the initiative to exclude the influence from the outside world. Thus, intellectual stimulation is not likely to influence employee self-development.

\subsection{The Influence of OCB on Employee Sustainable Performance}

The researchers find that OCB includes four dimensions. In the paths of influencing employee sustainable performance, all the paths are significantly positive, except for the path from "helping a co-worker" to "relation sustainable performance".

It is also found that OCB can act as a catalyst for organizational operations, less interpersonal conflicts, and create a pleasant working environment. Additionally, Organizational citizenship is conducive to creating the organization's social capital, thereby improving staff efficiency and organizational performance [52]. Generally speaking, OCB is both beneficial to task sustainable performance and relation sustainable performance.

"Helping a co-worker" cannot improve "relation sustainable performance", because in the context of Chinese culture, the help of colleagues is often attributed to the scope of private relations [54]. As such, the relationship between the organization and the leader is not close. Therefore, this path is not significant.

\subsection{The Mediating Role of $O C B$}

It can be seen from Table 1 that OCB has mediated more than half of the influence from transformational leadership to employee sustainable performance. In particular, in terms of the relationship between transformational leadership and task sustainable performance, the mediating proportion of OCB is obviously quite high.

There are two reasons for the above finding. Firstly, OCB offers opportunities for employees to sustainably self-develop, to face work problems independently, take more responsibility, and improve their own competency [51,52]. All of this is beneficial to task sustainable performance. For example, self-development will improve an employee's knowledge and work skills, eventually improving his or her profession sustainable development $[54,60]$. Secondly, all project management tasks cannot be broken down definitively and assigned to specific persons. Most project management tasks require the cooperation of project teams [5], which in turn is more reliant on OCB. Therefore, the relationship between transformational leadership and task sustainable performance is mostly mediated by OCB. 
Moreover, OCB has mediated a certain proportion of the influence from transformational leadership to employee relation sustainable performance. In fact, $\mathrm{OCB}$ is naturally connected to relational performance. Furthermore, OCB helps to create a harmonious atmosphere within the organization, encouraging co-workers to be more coherent and cooperative [53]. Therefore, employee relational performance is positively related to OCB.

\section{Conclusions}

Most research hypotheses have been testified to and proven. First, transformational leadership has been proved to have a positive influence on employee sustainable performance, except for the influence of inspirational motivation on task sustainable performance. The reason for this finding may be that project management tasks often need project team cooperation. Furthermore, it is interesting to note that transformational leadership has stronger influence on relation sustainable performance than on task sustainable performance. Transformational leaders attempt to link the leader and subordinates together, thus creating a cooperative and transformational atmosphere, all of which is beneficial to relation sustainable performance. Second, researchers have testified that transformational leadership has a positive influence on employee $\mathrm{OCB}$, except for the influence of idealized influence and intellectual stimulation on self-development. "Aesthetic fatigue" and the "stereotyped thinking patterns" of employees decrease the influence of the project manager's idealized influence. Third, employee OCB has a positive influence on employee sustainable performance, except for the influence of helping a co-worker on relation sustainable performance. In the context of Chinese culture, help from colleagues is often attributed to the scope of private relations. As such, the relationship between the organization and the leader is not so close. Fourth, the mediating role of OCB was proved. More than half of the influence of transformational leadership on employee sustainable performance was mediated by OCB. The mediating function of OCB on the relationship between transformational leadership and task sustainable performance is especially high, because OCB supplies opportunities for employees to improve their own work competency, while improving team cooperation.

Based on the background of a Chinese construction project, this study has a certain innovative significance in the study of the impact of transformational leadership (through the mediation of OCB) on employee performance.

While past research has focused on the direct relationship between transformational leadership and employee sustainable performance, research on the mediation of OCB has been rare [13-15]. What is more, there have been contradictory conclusions reached about the mediating role of OCB in the relationship between transformational leadership and employee sustainable performance. In the field of construction project management research, the study of OCB as a mediator of transformational leadership and employee performance has not yet been seen. This research innovatively examines the mediating role of OCB between transformational leadership and employee sustainable performance in contractors' project management teams. Our study enriches existing research into construction project leadership and employee performance, and our study also supplies support for former research that has been questioned [13]. It reminds both researchers and practitioners of paying attention to transformational leadership and stimulating OCB to improve employee sustainable performance.

Some unique findings were made in this study under the background of Chinese culture and construction projects. First, task sustainable performance has been proved to be not directly related to inspirational motivation. This is because project management tasks are often intertwined, and task completion is more reliant on team collaboration. Second, the influence of transformational leadership on relation sustainable performance is significantly stronger than the influence on task sustainable performance. This is because transformational leadership is more directly related to the leader-subordinate relationship and employee emotions. Third, idealized influence and intellectual stimulation are found to have no significant influence on employee self-development. "Aesthetic fatigue" and "stereotypical thinking" on the part of employees may be attributed to this phenomenon. Fourth, "helping a co-worker" cannot improve "relational performance". This is because, in the 
context of Chinese culture, the help of colleagues is often attributed to the scope of private relations. Finally, OCB mediates most of the influence of transformational leadership on employee sustainable performance. This is because OCB supplies opportunities for employees to improve their own competence and to improve team cooperation. These findings are useful for the project managers of contractors in the context of Chinese culture.

However, there are some limitations in this study that need to be resolved in future research. First, subject to objective conditions, this study collected a total of 389 questionnaires. Although in the view of statistical requirement research, the sample size is already large enough, a larger sample size would be helpful to improve the applicability of the findings. Second, there are no control variables (such as organizational characteristics or the personal characteristics of employees) in this research. In fact, the relationship between variables in this research may be different, depending on different project management teams with different average ages and education backgrounds.

Acknowledgments: This research was supported by the National Natural Science Foundation of China (Grant No. 71503171), and the Natural Science Foundation of Guangdong Province, China (Grant No. 848-0000082158).

Author Contributions: Weiping Jiang designed the study and completed the paper in English, Xianbo Zhao gave much research advice. Jiongbin Ni collected the questionnaires.

Conflicts of Interest: The authors declare no conflicts of interest.

\section{Appendix A}

Table A1. Summarization of hypotheses.

\begin{tabular}{|c|c|c|c|}
\hline \multicolumn{3}{|c|}{ Hypothesis } & Hypothesis Description \\
\hline \multicolumn{3}{|c|}{ H1a } & Idealized influence has positive influence on employees' task sustainable performance \\
\hline \multicolumn{3}{|c|}{$\mathrm{H} 1 \mathrm{~b}$} & inspirational motivation has positive influence on employees' task sustainable performance \\
\hline \multirow[t]{4}{*}{ H1 } & \multicolumn{2}{|c|}{ H1d } & individualized consideration has positive influence on employees' task sustainable performance; \\
\hline & \multicolumn{2}{|c|}{ H1e } & Idealized influence has positive influence on employees' relation sustainable performance \\
\hline & \multicolumn{2}{|c|}{ H1g } & intellectual stimulation behavior has positive influence on employees' relation sustainable performance \\
\hline & \multicolumn{2}{|c|}{ H1h } & individualized consideration has positive influence on employees' relation sustainable performance \\
\hline \multirow{9}{*}{$\mathrm{H} 2$} & \multirow{9}{*}{$\mathrm{H} 2 \mathrm{a}$} & H2a-1 & Idealized influence of project manager has positive influence on employees' taking initiative behavior \\
\hline & & $\mathrm{H} 2 \mathrm{a}-2$ & Idealized influence of project manager has positive influence on employees' helping coworker behavior \\
\hline & & H2a-6 & Inspirational motivation of project manager has positive influence on employees' helping behavior \\
\hline & & H2a-7 & $\begin{array}{l}\text { Inspirational motivation of project manager has positive influence on employees' participation in } \\
\text { group activities }\end{array}$ \\
\hline & & H2a-8 & Inspirational motivation of project manager has positive influence on employees' self-development behavior \\
\hline & & H2a-9 & $\begin{array}{l}\text { Intellectual stimulation behavior of project manager has positive influence on employees' taking } \\
\text { initiative behavior }\end{array}$ \\
\hline & & $\mathrm{H} 2 \mathrm{a}-10$ & $\begin{array}{l}\text { Intellectual stimulation behavior of project manager has positive influence on employee's helping } \\
\text { coworker behavior }\end{array}$ \\
\hline & & H2a-11 & $\begin{array}{l}\text { Intellectual stimulation behavior of project manager has positive influence on employee's participation in } \\
\text { group activities }\end{array}$ \\
\hline & & H2a-16 & Individual consideration of project manager has positive influence on employee's self-development behavior \\
\hline
\end{tabular}


Table A1. Cont.

\begin{tabular}{lll}
\hline Hypothesis & \multicolumn{1}{c}{ Hypothesis Description } \\
\hline & H2b-1 & Taking initiative behavior of employees has positive influence on task sustainable performance \\
\cline { 2 - 3 } $\mathrm{H} 2 \mathrm{~b}-2$ & Taking initiative behavior of employees has positive influence on relation sustainable performance \\
\cline { 2 - 3 } $\mathrm{H} 2 \mathrm{~b}-3$ & Helping coworker behavior of employees has positive influence on task sustainable performance \\
\cline { 2 - 3 } $\mathrm{H} 2 \mathrm{~b}-4$ & Helping coworker behavior of employees has positive influence on relation sustainable performance \\
\hline $\mathrm{H} 2 \mathrm{~b}-5$ & Participation in group activities of employees has positive influence on task sustainable performance \\
\hline $\mathrm{H} 2 \mathrm{~b}-6$ & Participation in group activities of employees has positive influence on relation sustainable performance \\
\hline $\mathrm{H} 2 \mathrm{~b}-7$ & Individualized consideration of employees has positive influence on task sustainable performance \\
\hline $\mathrm{H} 2 \mathrm{~b}-8$ & Individualized consideration of employees has positive influence on relation sustainable performance \\
\hline
\end{tabular}

Table A2. Path values.

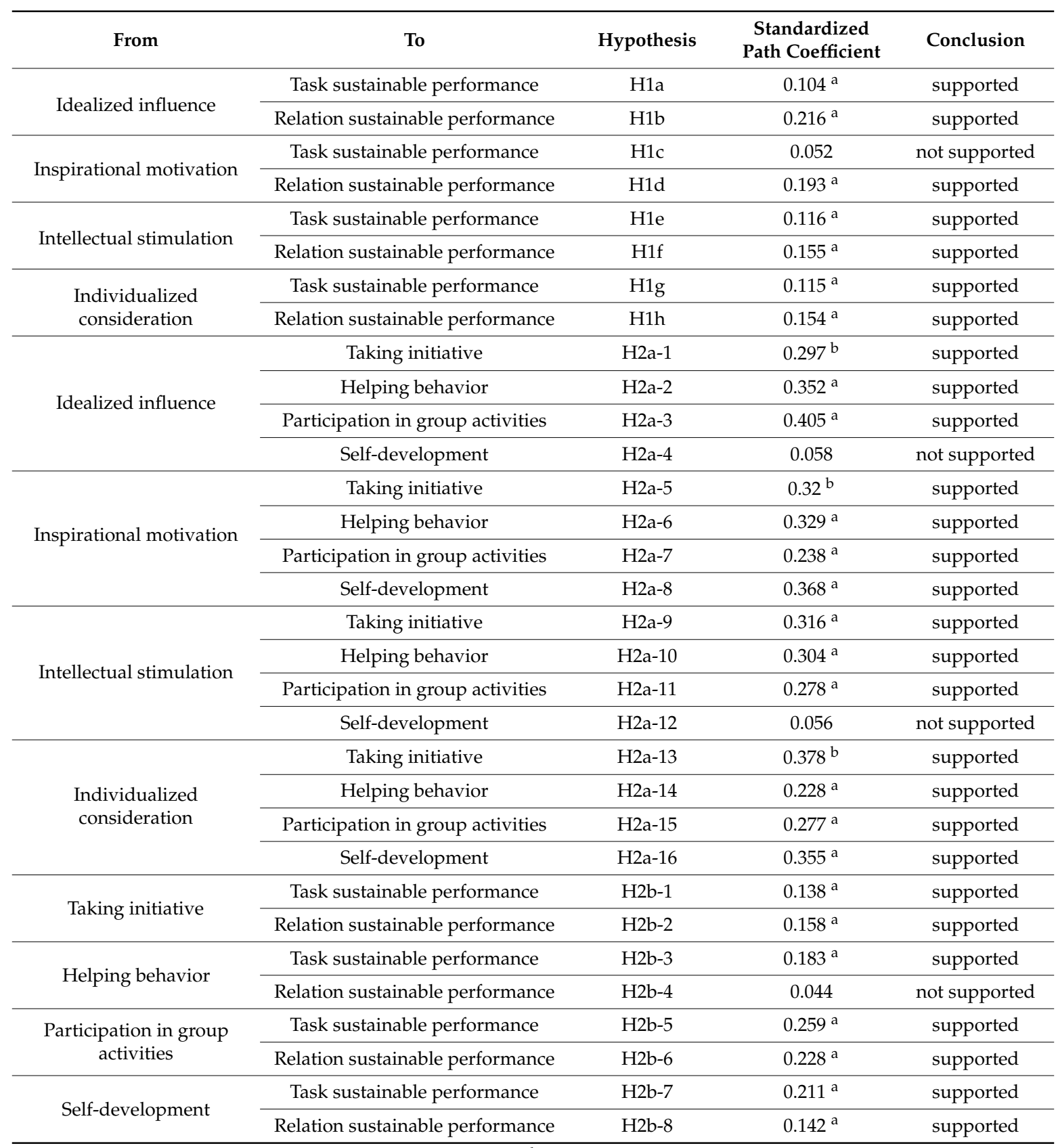

${ }^{a}$ Significant level is less than $0.05 ;^{\text {b }}$ Significant level is less than 0.10 . 


\section{References}

1. Larsson, J.; Eriksson, P.E.; Olofsson, T.; Simonsson, P. Leadership in civil engineering: Effects of project managers' leadership styles on project performance. J. Manag. Eng. 2015, 31, 04015011. [CrossRef]

2. Zuo, J.; Zhao, Z.Y. Green building research-Current status and future agenda: A review. Renew. Sustain. En. Rev. 2014, 30, 271-281. [CrossRef]

3. Shi, Q.; Yan, Y.; Zuo, J.; Yu, T. Objective conflicts in green buildings projects: A critical analysis. Build. Environ. 2016, 96, 107-117. [CrossRef]

4. Bass, B.M. Leadership performance beyond expectations. Acad. Manag. Rev. 1985, 12, 5244-5247.

5. Keegan, A.E.; Hartog, D.N.D. Transformational leadership in a project-based environment: A comparative study of the leadership styles of project managers and line managers. Int. J. Proj. Manag. 2004, 22, 609-617. [CrossRef]

6. Shi, D.; Adinolfi, V.; Comin, R.; Yuan, M.; Alarousu, E.; Buin, A.; Chen, Y.; Hoogland, S.; Rothenberger, A.; Katsiev, K. Low trap-state density and long carrier diffusion in organolead trihalide perovskite single crystals. Science 2015, 347, 519-522. [CrossRef] [PubMed]

7. Jiang, W.; Lu, Y.; Le, Y. Trust and project success: A twofold perspective between owners and contractors. J. Manag. Eng. 2016, 32, 04016022. [CrossRef]

8. Hwang, B.G.; Shan, M.; Supa'at, N.N.B. Green commercial building projects in Singapore: Critical risk factors and mitigation measures. Sustain. Cities Soc. 2017, 30, 237-247. [CrossRef]

9. Dvir, T.; Eden, D.; Avolio, B.J.; Shamir, B. Impact of transformational leadership on follower development and performance: A field experiment. Acad. Manag. J. 2002, 45, 735-744. [CrossRef]

10. Bass, B.M.; Avolio, B.J. Improving Organizational Effectiveness through Transformational Leadership; Sage: Thousand Oaks, CA, USA, 1993.

11. Zhang, X.; Cao, Q.; Tjosvold, D. Linking transformational leadership and team performance: A conflict management approach. J. Manag. Stud. 2011, 48, 1586-1611. [CrossRef]

12. Herman, H.M.; Huang, X.; Lam, W. Why does transformational leadership matter for employee turnover? A multi-foci social exchange perspective. Leadersh. Q. 2013, 24, 763-776.

13. Boerner, S.; Eisenbeiss, S.A.; Griesser, D. Follower behavior and organizational performance: The impact of transformational leaders. J. Leadersh. Organ. Stud. 2007, 13, 15-26. [CrossRef]

14. Ekowati, V.M.; Troena, E.A.; Noermijati, N. Organizational citizenship behavior role in mediating the effect of transformational leadership, job satisfaction on employee performance: Studies in PT Bank Syariah Mandiri Malang East Java. Int. J. Bus. Manag. 2013, 8, 17. [CrossRef]

15. Han, S.H.; Seo, G.; Yoon, S.W.; Yoon, D.Y. Transformational leadership and knowledge sharing: Mediating roles of employee's empowerment, commitment, and citizenship behaviors. J. Workplace Learn. 2016, 28, 130-149. [CrossRef]

16. Sparkling, A.E.; Mollaoglu, S.; Kirca, A. Research synthesis connecting trends in architecture, engineering, and construction project partnering. J. Manag. Eng. 2016, 33, 04016033. [CrossRef]

17. Shi, Q.; Liu, Y.; Zuo, J.; Pan, N.; Ma, G. On the management of social risks of hydraulic infrastructure projects in China: A case study. Int. J. Proj. Manag. 2015, 33, 483-496. [CrossRef]

18. Wang, H.; Law, K.S.; Hackett, R.D.; Wang, D.; Chen, Z.X. Leader-Member Exchange as a Mediator of the Relationship between Transformational Leadership and Followers' Performance and Organizational Citizenship Behavior. Acad. Manag. J. 2005, 48, 420-432.

19. Halbesleben, J.R.B.; Wheeler, A.R. To invest or not? The role of coworker support and trust in daily reciprocal gain spirals of helping behavior. J. Manag. 2015, 41, 1628-1650. [CrossRef]

20. Mhatre, K.H.; Riggio, R.E.; Handbooks, O. Charismatic and transformational leadership: Past, present, and future. In The Oxford Handbook of Leadership and Organizations; Oxford University Press: Oxford, UK, 2014; pp. 221-224.

21. Burns, J.M. Leadership New York; Harper and Row Publishers: New York, NY, USA, 1978.

22. Bass, B.M.; Riggio, R.E. Transformational Leadership; Psychol. Press: Hove, East Sussex, UK, 2006.

23. Bass, B.M.; Avolio, B.J. Transformational leadership and organizational culture. Int. J. Publ. Adm. 1994, 17, 541-554. [CrossRef]

24. Bass, B.M. Two decades of research and development in transformational leadership. Eur. J. Work Organ. Psychol. 1999, 8, 9-32. [CrossRef] 
25. Judge, T.A.; Piccolo, R.F. Transformational and transactional leadership: A meta-analytic test of their relative validity. J. Appl. Psychol. 2004, 89, 755. [CrossRef] [PubMed]

26. Cano, C.R.; Carrillat, F.A.; Jaramillo, F. A meta-analysis of the relationship between market orientation and business performance: evidence from five continents. Int. J. Res. Market. 2004, 21, 179-200. [CrossRef]

27. Barrick, M.R.; Mount, M.K. The big five personality dimensions and job performance: A meta-analysis. Pers. Psychol. 1991, 44, 1-26. [CrossRef]

28. Judge, T.A.; Thoresen, C.J.; Bono, J.E.; Patton, G.K. The job satisfaction-job performance relationship: A qualitative and quantitative review. Psychol. Bull. 2001, 127, 376-407. [CrossRef] [PubMed]

29. Zablah, A.R.; Bellenger, D.N.; Straub, D.W.; Johnston, W.J. Performance implications of CRM technology use: A multilevel field study of business customers and their providers in the telecommunications industry. Inf. Syst. Res. 2012, 23, 418-435. [CrossRef]

30. Katz, D.; Kahn, R.L. The social psychology of organizations. Adm. Sci. Q. 1978, 46, 118.

31. Borman, W.C.; Motowidlo, S.M. Expanding the criterion domain to include elements of contextual performance. In Personnel Selection in Organizations; Jossey-Bass: San Francisco, CA, USA, 1993; pp. 71-98.

32. Bozionelos, N.; Singh, S.K. The relationship of emotional intelligence with task and contextual performance: More than it meets the linear eye. Pers. Individ. Differ. 2017, 116, 206-211. [CrossRef]

33. Borman, W.C.; Motowidlo, S.J. Task performance and contextual performance: The meaning for personnel selection research. Hum. Perform. 1997, 10, 99-109.

34. Gerstner, C.R.; Day, D.V. Meta-analytic review of leader-member exchange theory: Correlates and construct issues. J. Appl. Psychol. 1997, 82, 827-844. [CrossRef]

35. Howell, J.M.; Hallmerenda, K.E. The ties that bind: The impact of leader-member exchange, transformational and transactional leadership, and distance on predicting follower performance. J. Appl. Psychol. 1999, 84, 680-694. [CrossRef]

36. Yammarino, F.J.; Dubinsky, A.J. Transformational leadership theory: using levels of analysis to determine boundary conditions. Pers. Psychol. 1994, 47, 787-811. [CrossRef]

37. Spangler, W.D.; Braiotta, L. Leadership and corporate audit committee effectiveness. Group Organ. Stud. 1990, 15, 134-157. [CrossRef]

38. Kener, E. Prediction of mortality in patient with CF. N. Engl. J. Med. 1992, 326, 1187-1192.

39. Bass, B.M. From transactional to transformational leadership: Learning to share the vision. Organ. Dyn. 1990, 18, 19-31. [CrossRef]

40. Sydow, J.; Lindkvist, L.; DeFillippi, R. Project-based organizations, embeddedness and repositories of knowledge. Org. Stud. 2004, 25, 1475-1489. [CrossRef]

41. Barber, E.; Warn, J. Leadership in project management: From firefighter to firelighter. Manag. Decis. 2005, 43, 1032-1039. [CrossRef]

42. Bass, B.M. Leadership: Good, better, best. Organ. Dyn. 1985, 13, 26-40. [CrossRef]

43. Brockhoff, K. On the novelty dimension in project management. Proj. Manag. J. 2006, 37, $26-36$.

44. Heinz, U.; Baga, T.; Gebert, D.; Kearney, E. Leadership and cooperation as success factors in innovative R\&D projects on electronic platforms. Team Perform. Manag. 2006, 12, 66-76.

45. Morgeson, F.P. The external leadership of self-managing teams: Intervening in the context of novel and disruptive events. J. Appl. Psychol. 2005, 90, 497-508. [CrossRef] [PubMed]

46. Goodman, R.A.; Goodman, L.P. Some management issues in temporary systems: A study of professional development and manpower-the theater case. Adm. Sci. Q. 1976, 21, 494-501. [CrossRef]

47. Emery, C.R.; Barker, K.J. The effect of transactional and transformational leadership styles on the organizational commitment and job satisfaction of customer contact personnel. J. Organ. Cult. Commun. Confl. 2007, 11, 77-90.

48. Zwikael, O.; Unger-Aviram, E. Hrm in project groups: The effect of project duration on team development effectiveness. Int. J. Proj. Manag. 2010, 28, 413-421. [CrossRef]

49. Cleland, D.I. Understanding project authority: Concept changes manager's traditional role. Bus. Horiz. 1967, 10, 63-70. [CrossRef]

50. Hodgetts, R.M. Leadership techniques in the project organization. Acad. Manag. J. 1968, 11, $211-219$. [CrossRef]

51. Braun, T.; Ferreira, A.I.; Sydow, J. Citizenship behavior and effectiveness in temporary organizations. Int. J. Proj. Manag. 2013, 31, 862-876. [CrossRef] 
52. Organ, D.W. Organizational Citizenship Behavior: The Good Soldier Syndrome; Lexington Books/DC Heath and Company: Lexington, KY, USA, 1988.

53. Podsakoff, P.M.; Mackenzie, S.B.; Paine, J.B.; Bachrach, D.G. Organizational citizenship behaviors: A critical review of the theoretical and empirical literature and suggestions for future research. J. Manag. 2000, 26, 513-563. [CrossRef]

54. Farh, J.-L.; Zhong, C.-B.; Organ, D.W. Organizational citizenship behavior in the People's Republic of China. Organ. Sci. 2004, 15, 241-253. [CrossRef]

55. Podsakoff, P.M.; MacKenzie, S.B.; Moorman, R.H.; Fetter, R. Transformational leader behaviors and their effects on followers' trust in leader, satisfaction, and organizational citizenship behaviors. Leadersh. Q. 1990, 1, 107-142. [CrossRef]

56. Wei, H.M.; Long, L.R. Effects of cognition-and affect-base trust in supervisors on task performance and OCB. Acta. Psychol. Sin. 2009, 41, 86-94. [CrossRef]

57. Smith, C.A.; Organ, D.W.; Near, J.P. Organizational citizenship behavior: Its nature and antecedents. J. Appl. Psychol. 1983, 68, 653-663. [CrossRef]

58. Dyne, L.V.; Lepine, J.A. Helping and Voice Extra-Role Behaviors: Evidence of Construct and Predictive Validity. Acad. Manag. J. 1998, 41, 108-119. [CrossRef]

59. Takeuchi, R.; Bolino, M.C.; Lin, C.C. Too many motives? The interactive effects of multiple motives on organizational citizenship behavior. J. Appl. Psychol. 2015, 100, 1239. [CrossRef] [PubMed]

60. Hart, T.A.; Gilstrap, J.B.; Bolino, M.C. Organizational citizenship behavior and the enhancement of absorptive capacity. J. Bus. Res. 2016, 69, 3981-3988. [CrossRef]

61. Farh, J.L.; Earley, P.C.; Lin, S.C. Impetus for action: A cultural analysis of justice and organizational citizenship behavior in Chinese society. Adm. Sci. Q. 1997, 42, 421-444. [CrossRef]

62. Khokhar, A.M.; Zia-ur-Rehman, M. Linking ethical leadership to employees' performance: Mediating role of organizational citizenship behavior and counterproductive work behavior. Pak. J. Commer. Soc. Sci. 2017, 11, 321-350.

63. Andrew, J.W.; Rebecca, J.R.; Shawn, A.S. Fitting engagement into a nomological network: The relationship of engagement to leadership and personality. J. Leadersh. Organ. Stud. 2011, 18, 522-537.

64. Eisenbeiß, S.A.; Boerner, S. A double-edged sword: Transformational leadership and individual creativity. Br. J. Manag. 2013, 24, 54-68. [CrossRef]

65. Avolio, B.J.; Yammarino, F.J. Operationalizing charismatic leadership using a levels-of-analysis framework. Leadersh. Q. 1990, 1, 193-208. [CrossRef]

66. Leedy, P.; Ormrod, J. Practice Research: Planning and Design, 11th ed.; Pearson Education: London, UK, 2016.

67. Abowitz, D.A.; Toole, T.M. Mixed method research: Fudamental issues of design, validity, and reliability in construction research. J. Constr. Eng. Manag. 2009, 136, 108-116. [CrossRef]

68. Yammarino, F.J.; Bass, B.M. Long-Term Forecasting of Transformational Leadership and Its Effects among Naval Officers: Some Preliminary Findings; Leadership Library of America: West Orange, NJ, USA, 1990.

69. Curran, P.J.; West, S.G.; Finch, J.F. The robustness of test statistics to nonnormality and specification error in confirmatory factor analysis. Psychol. Methods 1996, 1, 16-29. [CrossRef]

70. Muthén, L.K.; Muthén, B.O. How to use a monte carlo study to decide on sample size and determine power. Struct. Equ. Model. 2002, 9, 599-620. [CrossRef]

71. Han, Y.; Liao, J.Q. Model of development and empirical study on employee job performance construct. J. Manag. Sci. Chin. 2007, 10, 62-77.

72. Hair, J.F.; Black, W.C.; Babin, B.J.; Anderson, R.E.; Tatham, R.L. Multivariate Data Analysis; Pearson Prentice Hall: Upper Saddle River, NJ, USA, 2006.

73. Tabish, S.Z.S.; Jha, K.N. Success traits for a construction project. J. Constr. Eng. Manag. 2012, 138, 1131-1138. [CrossRef]

74. Wong, W.K.; Cheung, S.O.; Yiu, T.W.; Pang, H.Y. A framework for trust in construction contracting. Int. J. Proj. Manag. 2008, 26, 821-829. [CrossRef]

75. Medsker, G.J.; Williams, L.J.; Holahan, P.J. A review of current practices for evaluating causal models in organizational behavior and human resources management research. J. Manag. 1994, 20, 439-464. [CrossRef]

76. Shan, M.; Chan, A.P.C.; Le, Y.; Xia, B.; Hu, Y. Measuring corruption in public construction projects in China. J. Prof. Issues Eng. Educ. Pract. 2015, 141. [CrossRef] 
77. Chen, F.; Curran, P.J.; Bollen, K.A.; Kirby, J.; Paxton, P. An empirical evaluation of the use of fixed cutoff points in RMSEA test statistic in structural equation models. Sociol. Methods Res. 2008, 36, 462-494. [CrossRef] [PubMed]

78. Bollen, K.A. In A new incremental fit index for general structural equation models. Sociol. Methods Res. 1989, 17, 303-316. [CrossRef]

79. Hwang, B.G.; Shan, M.; Phua, H.; Chi, S. An exploratory analysis of risks in green residential building construction projects: The case of Singapore. Sustainability 2017, 9, 1116. [CrossRef]

(C) 2017 by the authors. Licensee MDPI, Basel, Switzerland. This article is an open access article distributed under the terms and conditions of the Creative Commons Attribution (CC BY) license (http:/ / creativecommons.org/licenses/by/4.0/). 